\title{
Amniotic membrane can be a valid source for wound healing
}

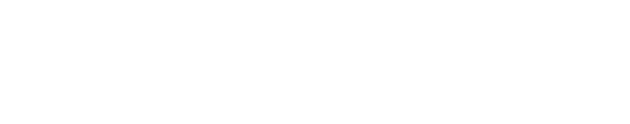

\section{Hossam ElHeneidy' \\ Eman Omran' \\ Ahmed Halwagy' \\ Hesham Al-Inany' \\ Mirvat Al-Ansary ${ }^{2}$ \\ Amr Gad ${ }^{3}$}

'Department of Obstetrics \& Gynecology, ${ }^{2}$ Department of Clinical Pathology, ${ }^{3}$ Department of Surgery, Faculty of Medicine, Cairo University, Cairo, Egypt

\section{Correspondence: Eman Omran} Department of Obstetrics \& Gynecology; Cairo University, 10 El-Ekhsheed street, Manial, Cairo II 1555, Egypt

Email omraneman9@gmail.com

\begin{abstract}
Amniotic membrane (AM) can promote proper epithelialization with suppression of excessive fibrosis by creating a supportive milieu for regeneration of chronic ulcer bed.

Objective: The objective of this study is to investigate whether AM scaffold can modulate the healing of a wound by promoting tissue reconstruction rather than promoting scar tissue formation.
\end{abstract}

Subjects and methods: AM was obtained and prepared and then applied to patients with chronic leg ulcers who were randomly divided into two different groups. Group I (control group) included eleven patients in whom ulcers were treated with conventional wound dressings that were changed daily for 8 weeks. Group II (study group) included 14 patients in whom the AM was placed in contact with the ulcer and held in place with a secondary dressing, which was changed daily. Follow-up was done to detect healing rate and detection of ulcer size, assessment of pain, and to take ulcer images (days $0,7,14,21,30,45$, and 60 ).

Results: In group I, all ulcers showed no reduction in their size, and ulcer floor remained the same. Healthy granulations were present in two ulcers (18.2\%) and absent in nine ulcers (81.8\%). There was no improvement of pain level in the eleven ulcers. In group II, complete healing of 14 ulcers occurred in 14-60 days with a mean of 33.3 \pm 14.7 ; healing rate range was $0.064-2.22$ and the mean $0.896 \pm 0.646 \mathrm{~cm}^{2} /$ day. Healthy granulations were present in 13 ulcers $(92.9 \%)$ and absent in one ulcer (7.1\%). Three ulcers $(21.4 \%$ ) were of mild severity (grade 1 ulcers) while eleven ulcers (78.6\%) were of moderate severity (grade 2 ulcers). The healing rate was faster in ulcers of mild severity $\left(1.7 \pm 0.438 \mathrm{~cm}^{2} /\right.$ day $)$ in comparison to ulcers of moderate severity $\left(0.673 \pm 0.498 \mathrm{~cm}^{2} /\right.$ day). Eleven cases (78.6\%) showed improvement in their pain level on a scale from 0 to 10 .

Conclusion: AM graft can be of value in wound healing. Further studies are needed to confirm these findings.

Keywords: amniotic membrane, ulcer, placenta, cesarean section

\section{Introduction}

Amniotic membrane (AM) is an attractive method of grafting for wounds as it has unique properties, including anti-inflammatory effects, bacteriostatic, wound protection, decreased scarring, and pain reduction properties, as well as epithelialization initialization capacities. Furthermore, AM is widely available and less costly than other bioengineered skin substitutes. Human AM was used for 2,308 ophthalmologic reconstructions in Germany 2008. ${ }^{1}$ Its special success in ophthalmology may be due to the immune privileged properties of the $\mathrm{AM}^{2}$

The anti-inflammatory property of AM seems to be a result of production of antiinflammatory proteins and reduction of expression of transforming growth factor $\mathrm{B}$ and pro-inflammatory cytokines, such as interleukin $10 .{ }^{3,4}$ Also, AM produces B defensins, elastase inhibitors, elastin, and lactoferrin that contribute to its anti-inflammatory 
and antimicrobial effects., ${ }^{5,6}$ The reduction in scarring after application of AM to wounds might be due to the antiinflammatory effects, acceleration of epithelialization, ${ }^{3,4,7}$ and inhibition of fibrosis. ${ }^{8}$ Accelerated reepithelialization was also demonstrated by Maral et $\mathrm{al}^{9}$ after covering split thickness skin graft with $\mathrm{AM}$ in rats. Loeffelbein et $\mathrm{al}^{10}$ demonstrated accelerated formation of basement membrane in wounds treated with AM that might be due to the release of growth factors. One of the most important properties of AM as a skin substitute is pain relieving which may be due to diminished inflammation, better hydration of wound bed, and protection of exposed nerve endings. ${ }^{10}$ AM expresses few antigens, which accounts for its good tolerability and the absence of rejection reactions. ${ }^{11}$ AM expresses many neurotrophic and angiogenic factors: endothelin-2 and -3, vascular endothelial growth factor, vascular endothelial growth factor-B, Tie-2 angiopoietin receptor, ephrin-A2, ephrin receptors A2, B1, B3, B4, B5, neuropilin-2, nerve growth factor receptor, and semaphorin-F19 as well as erythropoietin and its receptor that contribute to healing of wounds. ${ }^{12,13}$ Some studies demonstrated the effectiveness of AM graft for healing of wounds. Mermet et $\mathrm{al}^{14}$ put an AM graft for 15 chronic leg ulcers and healing occurred in all patients. Pesteil et al ${ }^{15}$ used cryopreserved AM in eight patients with resistant vascular ulcers. Tolerance to the graft was excellent with healing of six out of eight patients with significant improved pain. Alsina-Gibert and Pedregosa-Fauste ${ }^{16}$ used AM for four refractory ulcers with a mean $81.93 \%$ reduction of ulcer size after 16 weeks. Litwiniuk et al ${ }^{17}$ suggested the potential role of matrix metalloproteinase inhibitors present in radiation-sterilized amnion dressing in healing of 23 out of 25 patients with chronic venous ulcers. Sheikh et a ${ }^{18}$ used dehydrated amnion to provoke healing of chronic wounds in four patients and healed wounds did not recur on longterm follow-up. A similar study was done by Zelen et $\mathrm{al}^{19}$ who used dehydrated AM in diabetic foot ulcers with complete healing of 37 out of 40 ulcers. With respect to the low cost, wide availability, and easy preparation, AM can be an ideal graft for chronic refractory ulcers.

\section{Subjects and methods Study design}

This was an experimental, comparative, and randomized clinical trial.

\section{Description of patients and collection of data}

This study was performed to test a technique for the treatment of chronic nonhealing wounds using AM to express its effect on the rate of healing of such nonhealing ulcers. Patients were recruited from the outpatient clinics or the inpatient wards of the Department of General Surgery, Faculty of Medicine, Cairo University and Department of Vascular Surgery, Faculty of Medicine, Assiut University from June 2012 to June 2015. Each patient signed an informed consent after accepting to be enrolled in the study. Ethical aspects whether substantial or procedural have been implicated in this study and approval was obtained from the Faculty of Medicine, Ethical Committee of Cairo University (30-9-2012).

Patients were then randomly divided into two different groups. Group I (the control group) included eleven patients with eleven chronic leg ulcers in whom ulcers were treated with conventional wound dressings that were changed daily for 8 weeks. Group II (the study group) included 14 patients with 14 chronic leg ulcers. The AM was placed in contact with the ulcer and held in place with a secondary dressing, which was changed daily. Inclusion criteria were presence of leg ulcers for more than 3 months with no improvement despite standard treatment and age between 26 and 43 years. Exclusion criteria were ulcers with ongoing active infection and presence of diabetes. Full history taking and clinical assessment were done with special reference to previous treatment and surgery, diagnosed diabetes and/or hypertension, causes, types, and duration of ulcers present.

The follow-up during treatment period includes assessment of ulcer healing and pain. Ulcer healing was assessed using the percentage of the healed wound area and healing rate. Using ImageJ program (Rasband, W.S., ImageJ, US National Institutes of Health, Bethesda, Maryland, USA), the wound areas were analyzed and a percentage of the healed wound area was calculated, in respect to the original wound area and the final wound area after 2 weeks and at the end of 2 months according to the formula:

$$
\begin{gathered}
\text { Percentage of } \\
\text { healed wound area }
\end{gathered}=\frac{\text { Original wound area }- \text { Final wound area }}{\text { Original } \text { wound area }} \times 100
$$

The healing rate was then determined, in respect to the original wound area, and the final wound area reached according to the formula:

$$
\text { Healing rate }=\frac{\text { Original wound area }- \text { Final wound area }}{\text { Time consumed to reach final wound area }}
$$

The wound area is calculated by the formula for determining the area of an ellipse $(($ length $\times$ width $) \times \pi / 4) .{ }^{20}$ 
Results of measured ulcer area size were used for follow-up, and ulcers were categorized with respect to surface area, exudate, and type of wound tissue. A comparison of total measurements over time provided an indicator of improvement or deterioration in ulcer healing. Pain was assessed using a visual analog scale, where 0 represented no pain and 10 represented the worst pain. Each patient has a special file in which all the data were present. Then, merging of data of all patients was done before statistical analysis.

\section{$A M$ isolation, preservation, grafting, and follow-up of patients}

Human AM was prepared from placentae obtained from scheduled delivery by cesarean section following a noncomplicated pregnancy. Exclusion criteria were symptoms of infection in the newborn, delivery before 34 weeks gestation, and membrane rupture more than 12 hours before delivery. The donors gave written informed consent for the donation and use of the AM. One placenta can provide four to five AM tissue fragments $5 \mathrm{~cm}$ in diameter.

Preparation was performed in a classified (class D) room with a microbiological safety workstation (class A). The placenta was washed with physiological saline and left in contact with an antibiotic solution in its collection container until preparation within 2 hours of the cesarean delivery. The entire membrane structure was immersed in a sterile packing container. The AM is mixed with antibiotics and antifungal in the container. The AM was then cut into different sizes and AM tissue fragments were obtained (Figure 1). For cryopreservation of AM, a cryoprotective agent was added (Roswell Park Memorial Institute medium [RPMI] and glycerol), and then stored in a temperature of $-80^{\circ} \mathrm{C}$ with each piece of the AM stored in a separate container. Three AM samples are collected for bacteriological examination. The placenta rinse fluid $(8-10 \mathrm{~mL})$ was used to inoculate two vials of aerobic and anaerobic organisms for bacteriological testing. The placenta was also prepared for a pathological evaluation. On the day of the cesarean section, test tubes containing blood from the mother were collected for the following serology tests: HIV-1 and -2, Ag p24, HCV, HTLV; syphilis: VDRL-TPHA; and $\mathrm{HBV}$ : HBs antigen-HBc antibody. Final validation of the AM was performed after a repeat serology test by testing again the donor woman after 120 days. Before use, the AM can be transported to hospital and stored on dry ice up to 24 hours and conserved up to 2 hours in normal saline at room temperature after thawing before utilization.

The preparation of the ulcers includes cleaning and mechanical debridement with a scalpel. The membrane preservation solution was removed by washing with physiological saline and the membrane was applied directly onto the ulcer bed (Figure 2). The graft was then covered with vaseline dressing (Figure 3). Patients were confined to bed for 2 hours and then allowed to do moderate activity for the next 5 days.

Follow-up was done to detect healing rate and detection of ulcer size, assessment of pain, and to take ulcer images (days $0,7,14,21,30,45$, and 60). Statistical analyses of

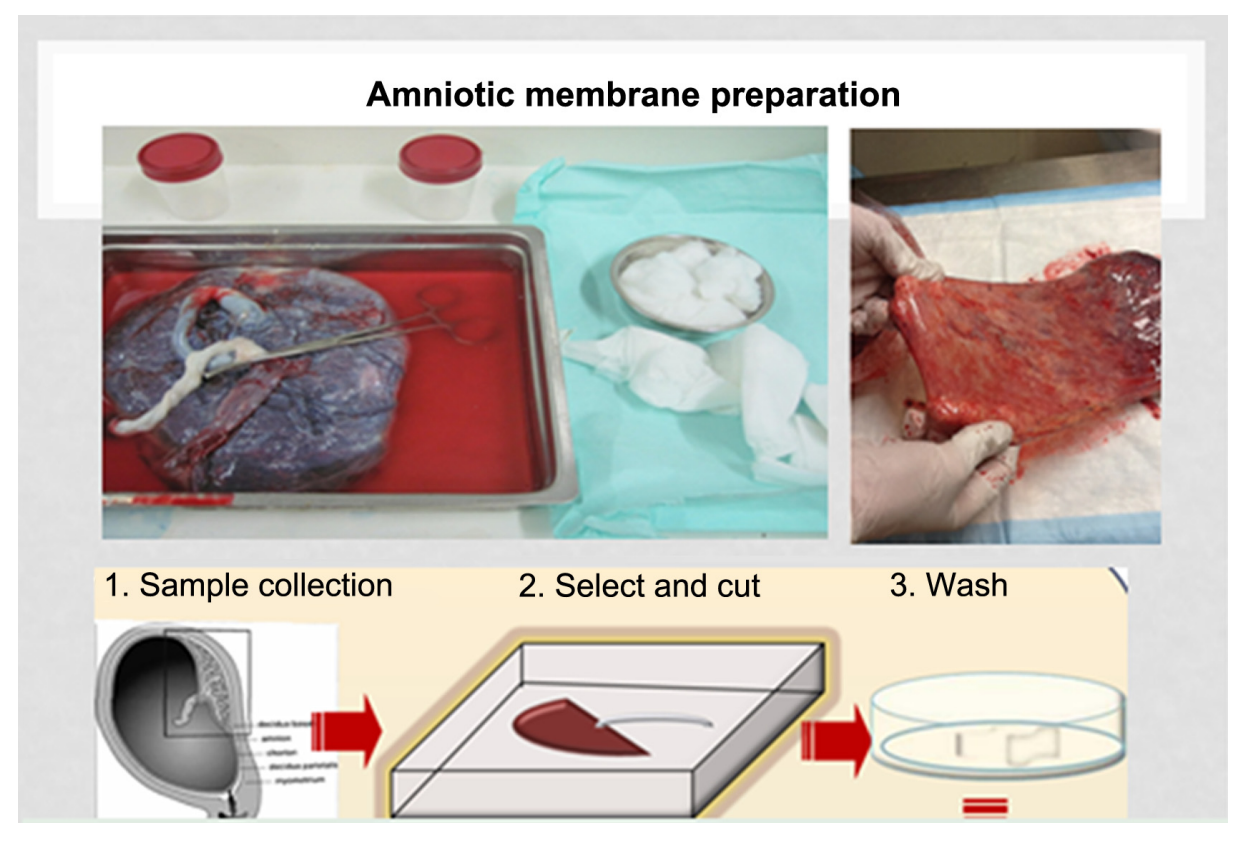

Figure I Preparation of amniotic membrane pieces. 

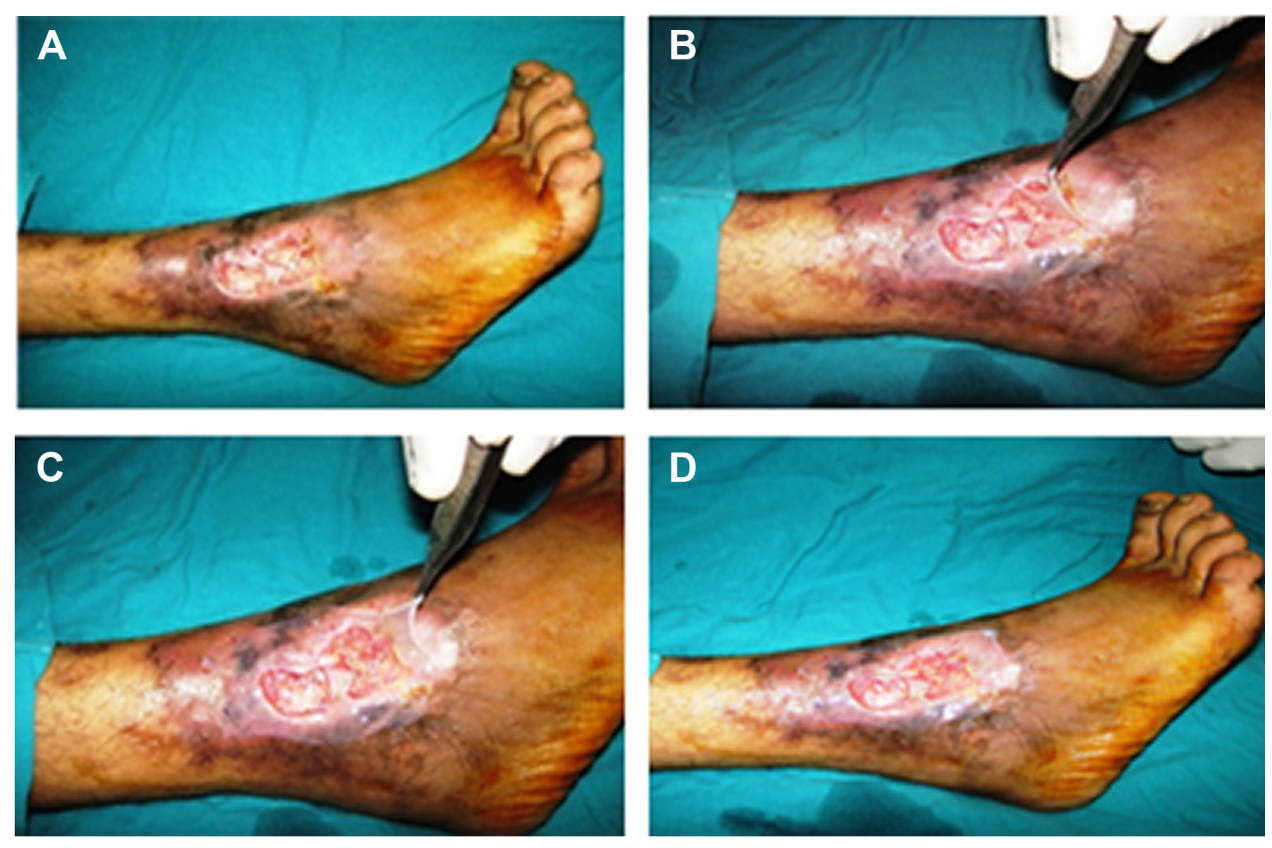

Figure 2 Amniotic membrane application over two leg ulcers.

Notes: Two leg ulcers in one patient (A); application of amniotic membrane over the leg ulcers (B and C); image of the patient after amniotic membrane grafting (D).

all data were performed with SPSS software version 15.0 for Windows (SPSS Inc, Chicago, IL, USA). A two-sided value of $P<0.05$ was considered statistically significant for all analyses. Continuous variables are presented as mean \pm standard deviation (SD).
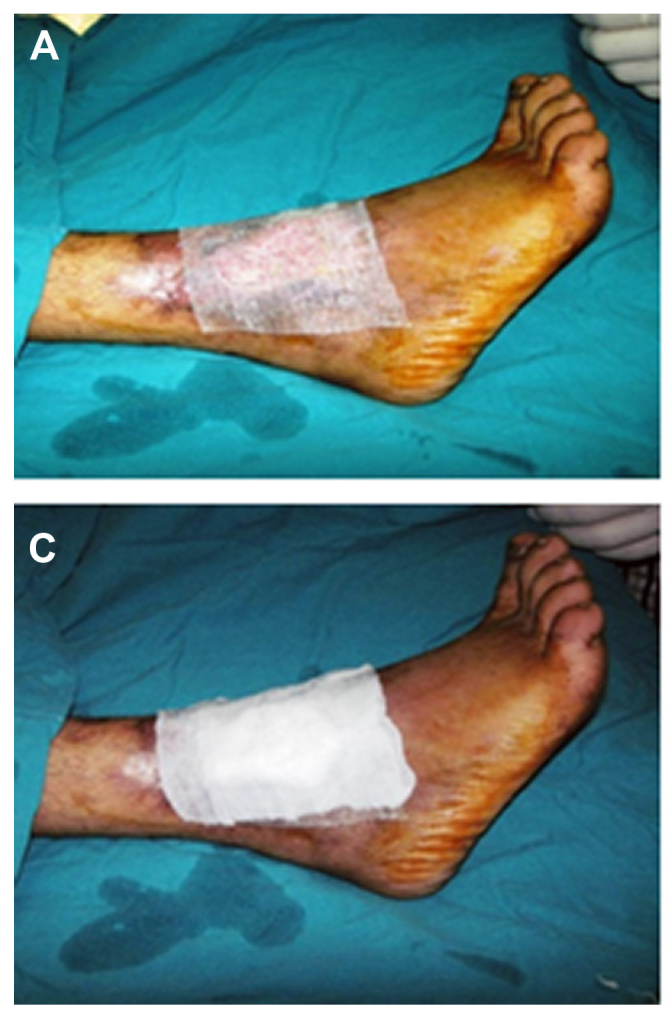

\section{Results}

\section{Demographic data of the sample}

All patients were males between 26 and 43 years. In group I, there were a total of eleven leg ulcers. Age ranged from 26 to 43 years with a mean value $34.45 \pm 7.03$. Nine ulcers
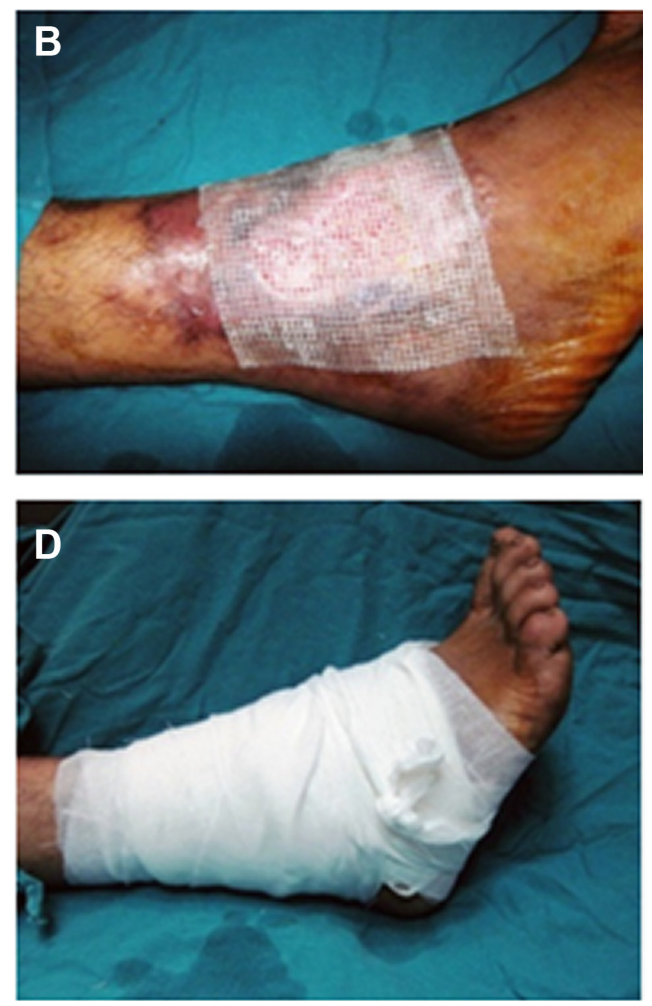

Figure 3 Vaseline dressing is added over amniotic membrane and then covered with dressing. Notes: Application of vaseline dressing (A and $\mathbf{B})$; application of gauze dressing after vaseline (C); gauze wrapping at the end (D). 
$(81.8 \%)$ were venous ulcers, while two ulcers $(18.2 \%)$ were traumatic ulcers. In group II, there were a total number of 14 leg ulcers. Age ranged from 26 to 43 years with a mean value $32.86 \pm 6.94$. Twelve ulcers (85.7\%) were venous ulcers, while two ulcers (14.3\%) were traumatic ulcers. All patients of groups I and II were nondiabetics, with no history of smoking, hypertension, or any other medical condition.

\section{Results of the study}

Only conventional treatment was performed for the control group. Chronicity of leg ulcers varied from 24 to 60 months. The ulcer area at the beginning of the study was $4.8 \pm 0.65 \mathrm{~cm}^{2}$ (mean $\pm \mathrm{SD}$ ). Mean percentage of healing rate was $0 \%$, and all ulcers in this group showed no reduction in their size (Tables 1 and 2), and ulcer floor remained the same. Healthy granulations were present in two ulcers (18.2\%) and absent in nine ulcers $(81.8 \%)$. There is no improvement of pain level in the eleven ulcers (Table 3).

In the study group, the AM was directly applied on leg ulcers. This group included 14 leg ulcers. Chronicity of leg ulcers varied from 24 to 84 months. The ulcer area at the start of the study was $5.1 \pm 0.48 \mathrm{~cm}^{2}$ (mean $\pm \mathrm{SD}$ ). Results obtained from the study group showed complete healing of 14 ulcers in 14-60 days with a mean of $33.3 \pm 14.7$; healing rate range was $0.064-2.22$ and mean $0.896 \pm 0.646 \mathrm{~cm}^{2} /$ day with a $100 \%$ reduction in ulcer size. Ulcer floor improved in all ulcers. Healthy granulations were present in 13 ulcers $(92.9 \%)$ and absent in one ulcer (7.1\%). Three ulcers $(21.4 \%)$ were of mild severity (grade 1 ulcers) while eleven ulcers $(78.6 \%)$ were of moderate severity (grade 2 ulcers). The healing rate was faster in ulcers of mild severity $\left(1.7 \pm 0.438 \mathrm{~cm}^{2} /\right.$ day $)$ in comparison to ulcers of moderate severity $\left(0.673 \pm 0.498 \mathrm{~cm}^{2} /\right.$ day $)$. Eleven cases $(78.6 \%)$ showed improvement in their pain level on a

Table I Chronicity of leg ulcers, reduction in ulcer size with treatment, and healing rate

\begin{tabular}{lll}
\hline $\begin{array}{l}\text { Parameters of } \\
\text { healing }\end{array}$ & Group I & Group II \\
\hline $\begin{array}{l}\text { Chronicity of leg ulcer } \\
\text { (range) }\end{array}$ & $24-60$ months & $24-84$ months \\
$\begin{array}{l}\text { Chronicity of leg ulcer } \\
\text { (mean }+\mathrm{SD} \text { ) }\end{array}$ & $45.82+14.01$ months & $50.57+16.43$ months \\
$\begin{array}{l}\text { Reduction of ulcer } \\
\text { size with treatment }\end{array}$ & $0 \%$ & $100 \%$ reduction \\
$\begin{array}{l}\text { Reduction of ulcer } \\
\text { size with treatment } \\
\text { (mean }+ \text { SD) }\end{array}$ & $0.0+0.0$ & $\begin{array}{l}100.0+0.0 \\
\text { Healing rate } \mathrm{cm}^{2} / \text { day } \\
\text { (range) }\end{array}$ \\
$\begin{array}{l}\text { Healing rate } \mathrm{cm}^{2} / \text { day } \\
\text { (mean }+\mathrm{SD} \text { ) }\end{array}$ & $0.0-0.0$ & $0.064-2.22$ \\
\hline
\end{tabular}

Abbreviation: SD, standard deviation.
Table 2 Percentage of healed ulcers

\begin{tabular}{lllll}
\hline Ulcer healing & Group I & \multicolumn{3}{c}{ Group II } \\
\hline No healing & II & $100 \%$ & 0 & $0 \%$ \\
Complete healing & 0 & $0 \%$ & 14 & $100 \%$ \\
Incomplete healing & 0 & $0 \%$ & 0 & $0 \%$ \\
\hline
\end{tabular}

Notes: Group I included patients without amniotic membrane application; while Group II included patients with amniotic membrane application.

scale from 1 to 10 . Three patients had no pain (Tables 1-3; Figure 4). AM graft was taken in four cases (28.6\%), while AM was not taken in ten cases $(71.4 \%)$ in the days following the graft application. In these ten cases, the ulcers also showed complete healing on follow-up. Reduction in ulcer size shows significant difference between group I (control group) in comparison to group II $(P=0.001)$ in which we used AM alone.

\section{Discussion}

Chronic leg ulcers are defined as a defect in the skin, below the level of the knee and above the foot, persisting for 6 weeks or more. ${ }^{21}$ A previous study found that $\sim 60 \%-80 \%$ of chronic leg ulcers had a venous component, 10\%-30\% was associated with arterial insufficiency, and other factors included diabetes mellitus and rheumatoid disease. Arterial and venous insufficiency combined in $10 \%-20 \%$ of cases. ${ }^{21}$

Chronic leg ulcers often heal poorly if there is no revascularization. Different lines of treatment are based on optimized local wound care: cleansing, debridement and dressings, compression therapy, and skin grafting. AM graft can be used as placental tissues contain a large quantity of growth factors. Furthermore, AM downregulates transforming growth factor (TGF)- $\beta$ and its receptor expression by fibroblasts and in doing so it reduces the risk of fibrosis. Therefore, an AM scaffold can modulate the healing of a wound by promoting tissue reconstruction rather than promoting scar tissue formation. ${ }^{3}$

AM is a natural scaffold, which is the supporting matrix upon which cells and tissues grow, and so it is considered an important component of tissue repair with multiple clinical applications. In addition, the AM has other biological properties important for tissue repair, including anti-inflammatory, antimicrobial, antifibrosis, antiscarring,

Table 3 Pain level improved or remained the same from day 0 till the end of study

\begin{tabular}{lllll}
\hline Pain level & Group I & \multicolumn{3}{c}{ Group II } \\
\hline No pain & 0 & $0.0 \%$ & 3 & $21.4 \%$ \\
Improved & 0 & $0.0 \%$ & II & $78.6 \%$ \\
The same & II & $100 \%$ & 0 & $0.0 \%$ \\
\hline
\end{tabular}



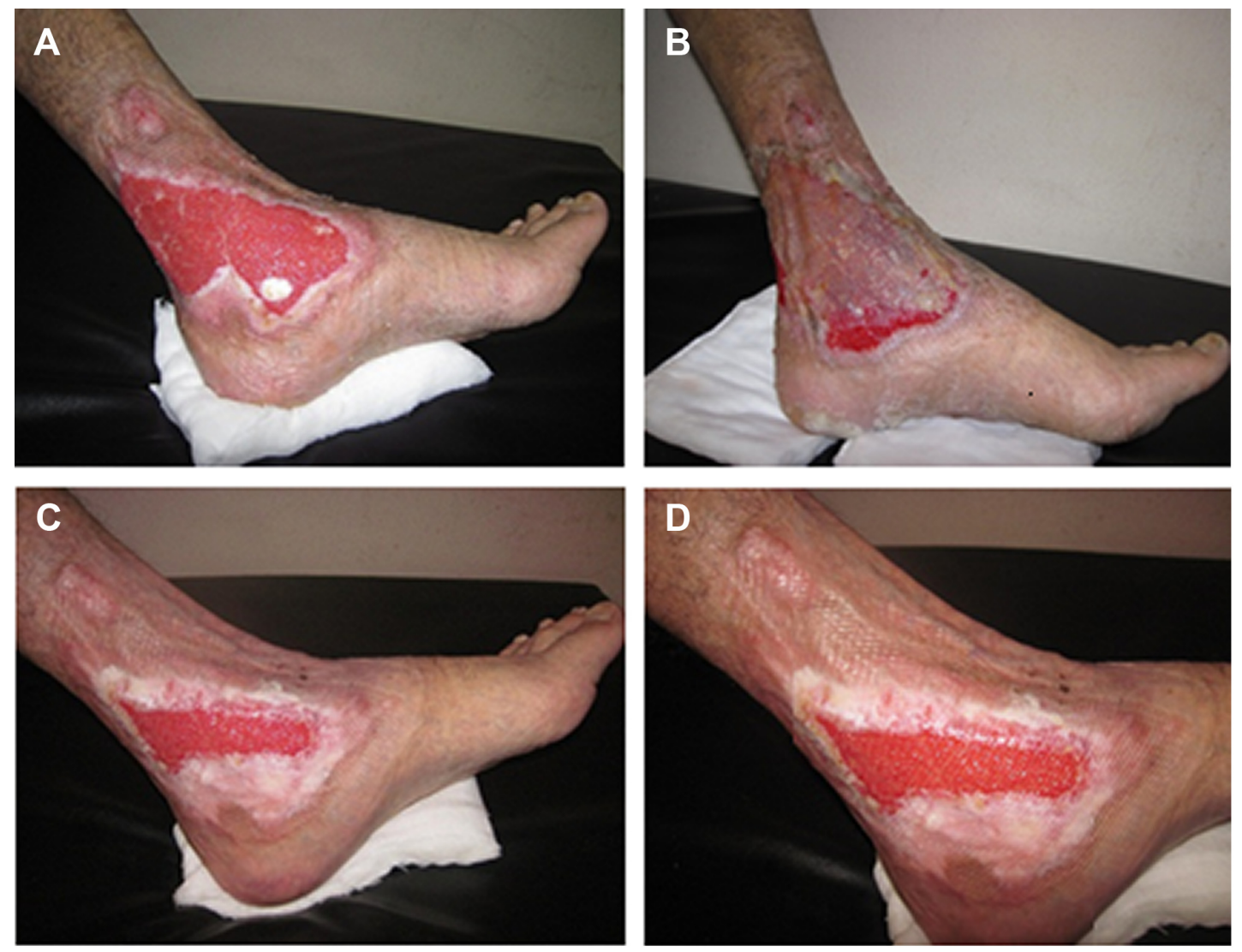

Figure 4 Healing of two leg ulcers after amniotic membrane application.

Notes: Two leg ulcers in one patient (A); application of amniotic membrane on the two ulcers (B); reduction in size of both ulcers (C); complete healing of the upper ulcer and $70 \%$ reduction in the size of the lower one on follow up (D).

and low immunogenicity as previously discussed. AM may thus be regarded as a bio-therapeutic product composed of a single layer of epithelial cells that lie on a basement membrane and of a nonvascular collagenous stroma. These three components give AM its beneficial properties, including antiadhesive effects, bacteriostatic properties, wound protection, pain reduction, and epithelialization effects. ${ }^{22-24}$

The AM epithelial cells reside on the inner layer of the $\mathrm{AM}$, while amniotic mesenchymal stromal cells form the outer layer. ${ }^{25}$

Results obtained from our study group showed complete healing of 14 ulcers in 14-60 days with a mean of $33.3 \pm 14.7$; healing rate range was $0.064-2.22$ and mean $0.896 \pm 0.646 \mathrm{~cm}^{2} /$ day with a $100 \%$ reduction in ulcer size. Ulcer floor improved in all ulcers. Healthy granulations were present in 13 ulcers $(92.9 \%)$ and absent in one ulcer (7.1\%). Three ulcers (21.4\%) were of mild severity (grade 1 ulcers) while eleven ulcers $(78.6 \%)$ were of moderate severity (grade 2 ulcers). Eleven cases (78.6\%) showed improvement in their pain level on a scale from 1 to 10 . AM graft was taken in four cases (28.6\%), while AM was not taken in ten cases $(71.4 \%)$.
The current study results were supported by the results of Mermet et $\mathrm{al}^{14}$ in a prospective pilot study, in which they evaluated the safety, feasibility, and the effects on healing of AM graft in 15 patients with chronic venous leg ulcers. The percentage of granulation tissue increased significantly (from $17 \%$ on day 0 to $69 \%$ on day $14, P<0.0001$ ), along with a significant decrease of fibrinous slough (from $36 \%$ at day 0 to $16 \%$ at day $14, P<0.001)$. There was significant reduction in ulcer size and pain level as well. Also, AlsinaGibert and Pedregosa-Fauste ${ }^{16}$ performed AM transplantation for four refractory vascular ulcers. Complete wound reepithelialization was achieved for one ulcer by week 8 ; in the other three cases, there was a $50 \%$ reduction in size compared to baseline. At week 16, the mean reduction in wound size for the four ulcers was $81.93 \%$. The corresponding reduction in pain intensity was $86.6 \%$. No adverse effects were observed.

To our knowledge, this is the first study to prove the possible efficacy of AM in treating nonvascular (traumatic) refractory wounds (two cases in this study) in addition to efficacy in treating vascular refractory ulcers (12 cases in this study) that was shown by previous similar studies. The 
limitation of this study is the small number that needs further studies to support it.

\section{Conclusion}

AM graft can be an ideal choice instead of tissue-engineered skin equivalents to be used in wound healing. In addition to being an excellent scaffold, it has unique biological properties that are important for tissue repair, including antiinflammatory, antimicrobial, antifibrosis, antiscarring, as well as a reasonable cost and low immunogenicity. Furthermore, presence of its own progenitor cells help in tissue repair.

\section{Recommendations and implications to practice}

Further studies should be done to support this study results. Comparing AM with alternative allogeneic or autologous skin substitutes in a randomized study will be worthwhile to determine the best therapeutic option and establish the potential of using AM in the treatment of leg ulcers. Routine preparation and preservation of AM will be of great value in tissue repair programs and implementation of biotherapy especially in developing countries due to its efficacy and low cost.

\section{Disclosure}

The authors report no conflicts of interest in this work.

\section{References}

1. Meller D, Pauklin M, Thomasen H, Westekemper H, Steuhl K-P. Amniotic membrane transplantation in the human eye. Dtsch Ärztebl Int. 2011;108:243-248.

2. Kubo M, Sonoda Y, Muramatsu R, Usui M. Immunogenicity of human amniotic membrane in experimental xenotransplantation. Invest Ophthalmol Vis Sci. 2001;42:1539-1546.

3. Tseng S, Li D, Ma X. Suppression of transforming growth factor-beta isoforms, TGF-beta receptor type II, and myofibroblast differentiation in cultured human corneal and limbal fibroblasts by amniotic membrane matrix. J Cell Physiol. 1999;179(3):325-335.

4. Hao Y, Ma D, Hwang D, Kim W, Zhang F. Identification of antiangiogenic and antiinflammatory proteins in human amniotic membrane. Cornea. 2000;19(3):348-352.

5. Šplíchal I, Trebichavský I. Cytokines and other important inflammatory mediators in gestation and bacterial intraamniotic infections. Folia Microbiologica. 2001;46(4):345-351.

6. Kanyshkova T, Buneva V, Nevinsky G. Lactoferrin and its biological functions. Biochemistry (Moscow). 2001;66(1):1-7.
7. Lo V, Pope E. Amniotic membrane use in dermatology. Int J Dermatol. 2009;48(9):935-940.

8. Kim J, Kim J, Na B, Jeong J, Song S. Amniotic membrane patching promotes healing and inhibits proteinase activity on wound healing following acute corneal alkali burn. Exp Eye Res. 2000;70(3):329-337.

9. Maral T, Borman H, Arslan H, Demirhan B, Akinbingol G, Haberal M. Effectiveness of human amnion preserved long-term in glycerol as a temporary biological dressing. Burns. 1999;25:625-635.

10. Loeffelbein D, Rohleder N, Eddicks M, et al. Evaluation of human amniotic membrane as a wound dressing for split-thickness skin-graft donor sites. Biomed Res Int. 2014;2014:572183.

11. Singh R, Chouhan U, Purohit S, et al. Radiation processed amniotic membranes in the treatment of nonhealing ulcers of different etiologies. Cell Tissue Bank. 2004;5:129-134.

12. Marvin K, Keelan J, Eykholt R, Sato T, Mitchell M. Expression of angiogenic and neuotrophic factors in the human amnion and choriodecidua. Am J Obstet Gynecol. 2002;187:728-734.

13. Toda A, Okabe M, Yoshida T, Nikaido T. The potential of amniotic membrane/amnion-derived cells for regeneration of various tissues. J Pharmacol Sci. 2007;105:215-228.

14. Mermet I, Pottier N, Sainthillier JM, et al. Use of amniotic membrane transplantation in the treatment of venous leg ulcers. Wound Repair Regen. 2007;15:459-464.

15. Pesteil F, Oujaou-Faïz K, Drouet M, et al. Cryopreserved amniotic membranes use in resistant vascular ulcers. J Mal Vasc. 2007;32(4-5): 201-209.

16. Alsina-Gibert M, Pedregosa-Fauste S. Amniotic membrane transplantation in the treatment of chronic lower limb ulcers. Actas Dermosifiliogr. 2012;103(7):608-613.

17. Litwiniuk M, Bikowska B, Niderla-Bielińska J, et al. Potential role of metalloproteinase inhibitors from radiation sterilized amnion dressings in the healing of venous leg ulcers. Mol Med Rep. 2012;6(4):723-728.

18. Sheikh E, Sheikh E, Fetterolf D. Use of dehydrated human amniotic membrane allografts to promote healing in patients with refractory non healing wounds. Int Wound J. 2014;11(6):711-717.

19. Zelen CM, Serena TE, Snyder RJ. A prospective, randomised comparative study of weekly versus biweekly application of dehydrated humanamnion/chorion membrane allograft in the management of diabetic foot ulcers. Int Wound J. 2014;11(2):122-128.

20. Stacey M, Burnand K, Layer G, Pattison M, Browse NL. Measurement of the healing of venous ulcers. Aust N Z J Surg. 1991;61(11):844-848.

21. Nelzén O, Bergqvist D, Lindhagen A. Leg ulcer etiology - a cross sectional population study. J Vasc Surg. 1991;14(4):557-564.

22. Azuara-Blanco A, Pillai CT, Dua HS. Amniotic membrane transplantation for ocular surface reconstruction. Br J Ophthalmol. 1999;83: 399-402.

23. Gomes J, Romano A, Santos M, Dua H. Amniotic membrane use in ophthalmology. Curr Opin Ophthalmol. 2005;16:233-240.

24. Alio JL, Abad M, Scorsetti DH. Preparation, indications and results of human amniotic member transplantation for ocular surface disorders. Expert Rev Med Devices. 2005;2:153-160.

25. Mamede A, Carvalho M, Abrantes A, Laranjo M, Maia C, Bothelho M. Amniotic membrane; from structure and functions to clinical applications. Cell Tissue Res. 2012;349:2447-458.

\section{Dovepress}

\section{Publish your work in this journal}

The International Journal of Women's Health is an international, peerreviewed open-access journal publishing original research, reports, editorials, reviews and commentaries on all aspects of women's healthcare including gynecology, obstetrics, and breast cancer. The manuscript management system is completely online and includes a very quick and fair peer-review system, which is all easy to use. Visit http://www.dovepress.com/testimonials.php to read real quotes from published authors. 